frequent development of tachyphylaxis apart from numerous other toxic reactions and the painfulness of the injections. The main advantage of dimercaprol is that the molecule is not charged, is soluble in lipids, and is able to cross the blood-brain barrier fairly easily compared with penicillamine, trientine dihydrochloride, and unithiol, which are highly charged.

Treatment with unithiol was started in two other patients. The first developed a fever of $39^{\circ} \mathrm{C}$ four hours after the test dose and a $50 \%$ fall in the leucocyte count. A further challenge dose caused a similar reaction and treatment was not pursued. This patient was subsequently managed with tetrathiomolybdate. ${ }^{3}$ The second patient took unithiol for 10 days before refusing it because of intense nausea and a change in taste. Other patients have received single test doses, and the resulting cupruresis has been comparable with that after penicillamine and trientine dihydrochloride in most cases. Unithiol may well prove to be yet one more fall back treatment for patients who develop intolerance to penicillamine.

I thank Dr A M Bennett of Mercy Hospital, Cork, for referring this patient and for the biochemical findings before treatment; and Dr E Heyl of Heyl Chemisch-pharmazeutische Fabrik, Berlin, for generous supplies of Dimaval.

1 Walshe JM. Penicillamine and the SLE syndrome. F Rheumatol 1981 ;8(suppl 7):

2 Shouwink G. De hépato-cérébrale dégénératie. Arnhem: Van Der Wiel, 1961

Walshe JM. Copper: its role in the pathogenesis of liver disease. Semin Liver Dis $1984 ; 4: 252-63$

4 Walshe JM. Wilson's disease: genetics and biochemistry: their relevance to therapy. $\mathcal{F}$ Inherit Dis $1983 ; 6$ (suppl 1):51-8.

(Accepted 14 fanuary 1985)

University of Cambridge Clinical School, Department of Medicine, Level 5, Addenbrooke's Hospital, Cambridge CB2 2QQ

J M WALSHE, SCD, FRCP, reader in metabolic disease

\section{Bronchoconstriction in response to suggestion: its prevention by an inhaled anticholinergic agent}

Emotion is a recognised trigger factor in asthma, yet few studies have examined the mechanism. Luparello et al first showed that many asthmatics would respond with bronchoconstriction if it was suggested to them that saline was a bronchoconstrictor drug. ${ }^{1}$ This response was prevented by intravenous atropine. ${ }^{2}$ This work has been challenged ${ }^{3}$ and the observed bronchoconstriction attributed to cooling of the airway by the inhaled saline. We have tried to establish whether suggested asthma exists and whether an inhaled anticholinergic drug prevents it.

\section{Patients, methods, and results}

Twenty five asthmatics (six men, 19 women; mean age 30 years, range 18-65) who described attacks precipitated or exacerbated by emotion were studied on three afternoons. Control forced expiratory volume in one second $\left(\mathrm{FEV}_{1}\right)$ on each study day was within $85 \%$ of predicted and $5 \%$ of the other study days; bronchodilator treatment was withheld for appropriate lengths of time. Subjects were informed that we were studying the effects of previous inhaler treatment on their response to known bronchoconstrictor and bronchodilator drugs. Ethical approval was obtained from the Research (Endowments) Committee of St Thomas's Hospital.

Each day $\mathrm{FEV}_{1}$ was measured every five minutes until two successive readings were within $5 \%$; the mean was taken as control. On days 1 and 2 subjects inhaled either $80 \mu \mathrm{g}$ ipratropium bromide or two puffs placebo in a randomised double blind crossover fashion and on all days rested for 30 minutes. They then received eight saline inhalations, each given over two minutes and separated by three minutes' rest. The subjects inhaled tidal breaths from a DeVilbiss 646 nebuliser which delivered phosphate buffered saline, using compressed air at $81 / \mathrm{min}, 1.4 \mathrm{~kg} / \mathrm{cm}^{2}(20 \mathrm{psi})$. The air passed through a water bath at $85^{\circ} \mathrm{C}$ and the saline heated to $67^{\circ} \mathrm{C}$ producing an aerosol at $32^{\circ} \mathrm{C}$. FEV 1 was measured in each rest period 30 seconds and 90 seconds after inhalation had stopped. The lowest value was recorded and the percentage change in $\mathrm{FEV}_{1}$ from control calculated.

On days 1 and 2, during the first two inhalations (period 1), subjects were shown a placard stating "This drug should not affect your breathing," during the next four inhalations (period 2) a series of placards suggesting that they were receiving doubling concentrations of a solution which could cause "breathlessness, tightness, or wheeze," and during the last two inhalations (period 3) one stating "This drug will relieve your tightness and your breathing will return to normal." On the control day subjects were shown the placard from period 1 throughout.

Ten asthmatics produced a fall in FEV 1 of greater than $15 \%$ when saline inhalation was accompanied by suggestion that it would cause wheeze. The remaining 15 showed no change in $\mathrm{FEV}_{1}$ on any study day. There were no significant differences in physical characteristics or of psychological and emotional trigger factor scores between the two groups. In the 25 asthmatics $\mathrm{FEV}_{1}$ on the ipratropium bromide day was 3.10 (SEM 0.14) 1 (95.0 (SEM $2 \cdot 1) \%$ predicted) before and $3 \cdot 18(0 \cdot 40) 1(97 \cdot 2(2 \cdot 3) \%$ predicted) after treatment.

In the bronchoconstrictor group (figure) $\mathrm{FEV}_{1}$ fell by 17.8 (SEM 3.5) $\%$ $(p<0.001)$ when saline was accompanied by bronchoconstrictor suggestion on the placebo inhaler day. This fall was abolished by ipratropium bromide and no change in $\mathrm{FEV}_{1}$ occurred with neutral suggestion on the control day. On the placebo day the bronchoconstriction was reversed when saline was inhaled with bronchodilator suggestion.

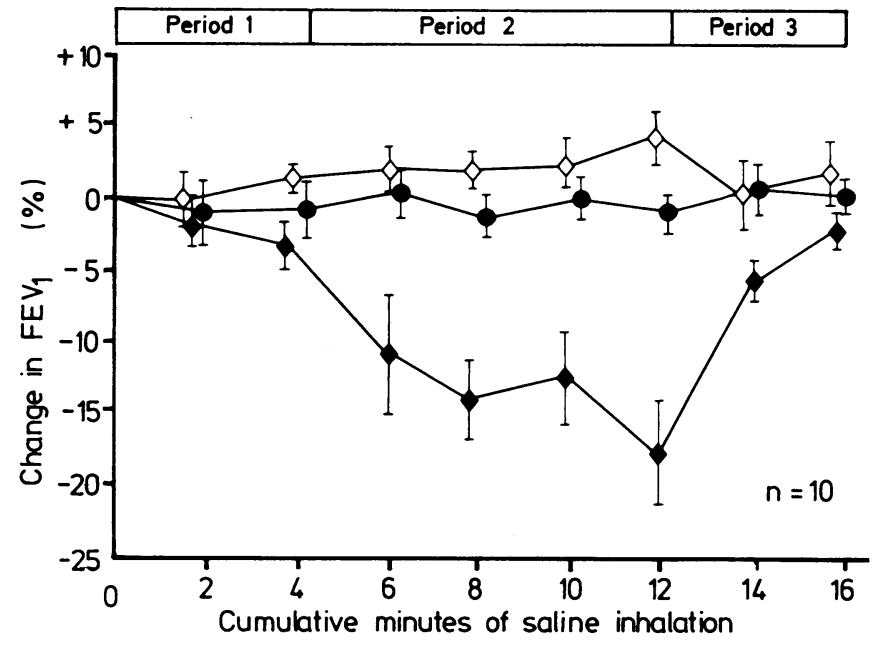

Changes in $\mathrm{FEV}_{1}$ after saline inhalation in bronchoconstrictor group. During period 1 saline was inhaled with suggestion that it would have no effect, during period 2 that it was a bronchoconstrictor, and in period 3 that it was a bronchodilator. $\diamond$ Ipratropium bromide day. Placebo day. - Control day. Results expressed as means and SEM.

\section{Comment}

This study shows that in a highly selected group of asthmatics bronchoconstriction can be produced by appropriate suggestion, confirming previous work. ${ }^{12}$ We found no evidence that it is due to airway cooling. Bronchoconstriction occurred despite the aerosol being heated to $32^{\circ} \mathrm{C}$ throughout. No bronchoconstriction occurred with two initial doses of saline without suggestion, or when, on the control day, saline was inhaled in the guise of a neutral substance.

Inhalation of saline accompanied by suggestion may provide a model for emotionally triggered asthma. Previous work showed that this bronchoconstriction could be prevented by intravenous atropine. ${ }^{2}$ We have found that it can also be prevented by inhaled ipratropium bromide. Whether this effect is specific to the anticholinergic effect of the drug or to a non-specific bronchodilator action remains to be shown.

JEN has been in receipt of grants from the Research (Endowments) Committee, St Thomas's Hospital, and the Asthma Research Council. Boehringer Ingelheim provided placebo and active ipratropium bromide inhalers.

1 Luparello T, Lyons HA, Bleecker ER, McFadden ER. Influences of suggestion on airway reactivity in asthmatic subjects. Psychosom Med 1968;30:819-25.

McFadden ER, Luparello T, Lyons HA, Bleecker ER. The mechanism of action of suggestion

3 Lewis RA, Lewis MN, Tattersfield AE. Asthma induced by suggestion: is it due to airway cooling? Am Rev Respir Dis 1984;129:691-5.

(Accepted 19 December 1984)

Department of Medicine, St Thomas's Hospital Medical School

(United Medical and Dental Schools), London SE1 7EH

J E NEILD, MB, MRCP, research registrar

I R CAMERON, DM, FRCP, professor of medicine

Correspondence to: Professor I R Cameron. 